\title{
Savoring Sport: Connections with Athlete Passion and Burnout
}

\author{
Benjamin J. I. Schellenberg ${ }^{1}$, Jérémie Verner-Filion ${ }^{2}$, and Patrick Gaudreau ${ }^{3}$ \\ ${ }^{1}$ Faculty of Kinesiology and Recreation Management, University of Manitoba \\ ${ }^{2}$ Département des sciences de L'éducation, Université du Québec en Outaouais \\ ${ }^{3}$ School of Psychology, University of Ottawa
}

\begin{abstract}
Author Note
Accepted author manuscript version reprinted, by permission, from the Journal of Clinical Sport Psychology, 2021 (ahead of print). (C) Human Kinetics, Inc.

Funding for this research was provided by the Social Sciences and Humanities Research Council of Canada (430-2018-00275). We thank Jack Lötscher, Sophia Mbabaali, Samantha Onchulenko, Allen Quach, Cody Rogers, Alana Signore for their assistance with manuscript preparation and data collection.

Correspondence concerning this article should be addressed to Benjamin Schellenberg, Faculty of Kinesiology and Recreation Management, University of Manitoba, Winnipeg, MB, R3T 2N2. Email: ben.schellenberg@umanitoba.ca
\end{abstract}




\begin{abstract}
Athletes can respond to positive experiences in sport by engaging in savoring - that is, by attempting to prolong or amplify their positive feelings (Bryant \& Veroff, 2007). In this research, we tested if savoring was predicted by levels of harmonious or obsessive passion for sport, and if savoring was associated with symptoms of burnout. In Study $1(n=499)$ we found that savoring was positively associated with harmonious passion and negatively associated with obsessive passion. In addition, savoring predicted lower levels of burnout and played an indirect role in the relationship between both passion types and burnout. We replicated these findings in Study 2 ( $n$ =298), with collegiate-level athletes prospectively over the course of a season. Overall, athletes with strong levels of harmonious passion appear to be most likely to engage in savoring, a response that may protect them from experiencing higher levels of burnout.

Keywords: emotion regulation, mediation, harmonious passion, obsessive passion, student-athletes
\end{abstract}




\section{Savoring Sport: Connections with Athlete Passion and Burnout}

Athletes have all kinds of positive experiences in sport: they are selected to elite teams, set personal bests and world records, execute difficult skills or maneuvers, make new friends, travel to new places, and of course win games and sometimes even championships. Athletes can make the most of these good times by savoring them. Savoring involves any response that attempts to maintain, prolong, or enhance positive experiences, including sharing an experience with others, becoming absorbed in the moment, verbally or physically expressing one's joy, and reflecting on the meaning of a positive experience (Bryant \& Veroff, 2007). But athletes likely vary in the extent to which they savor the good things that happen in their sport. Research in other areas has found that people who pursue meaningful activities with high levels of harmonious passion (HP) engage in greater levels of savoring, whereas those who pursue activities with high levels of obsessive passion (OP) savor positive experiences to a lesser extent (Schellenberg \& Gaudreau, 2020). This means athletes with high levels of HP may be most likely to engage in savoring. The more athletes savor positive moments, the more they may, in turn, feel accomplished and successful in their sport, that their sport is a valuable and important activity, and perhaps even physically and emotionally energized. Put differently, savoring may help athletes avoid experiencing burnout. Our aim in this research was to test if different forms of passion predicted different levels of savoring, and if savoring, in turn, predicted athlete burnout.

\section{Savoring and Passion}

Savoring is a way of regulating positive emotions that predicts various dimensions of well-being. Savoring has been associated with greater feelings of happiness shortly after positive events (Jose et al., 2012), greater life satisfaction (Hurley \& Kwon, 2013; Schellenberg \& 
Gaudreau, 2020), and lower levels of negative affect, stress, and depression (Bryant, 2003; Hurley \& Kwon, 2012; Wilson et al., 2020). Savoring has also been shown to buffer the impact that negative life events have on negative emotional reactions and mental health symptoms (Sytine et al., 2018; 2019). Despite these known benefits, little research has studied savoring among athletes. Recently, Doorley and Kashdan (2021) reported the results of a two-week daily diary study with a sample of college athletes. They found that savoring enhanced the association between daily positive events and positive emotional reactions including happiness, gratitude, and contentment. They also found that savoring buffered the effect that daily negative events had on negative emotional reactions including anger and annoyance. The results of this study, along with findings that have emerged outside of sport, suggest that savoring positive experiences may have many benefits for athletes.

Research has shown that savoring is associated with individual difference variables including personal resiliency, trait self-esteem, extraversion, optimism, hopelessness, and neuroticism (Bryant, 2003; Wilson \& Saklofske, 2018; Wood et al., 2003). When engaging in favorite activities, savoring has also been linked to the extent to which one's passion for an activity is harmonious or obsessive. The dualistic model of passion (Vallerand, 2015) identifies passion as a strong inclination toward an activity that one likes, values, pursues on a regular basis, and is part of one's identity. The model, however, distinguishes between two dimensions of passion, HP and OP, based on how an activity is internalized. An HP entails an autonomous internalization, meaning that the activity is freely accepted into one's identity and is pursued with a sense of personal volition. An OP, in contrast, entails a controlled internalization, meaning that one feels pressured to pursue an activity and that it is not fully integrated with one's true self. This means that, although HP and OP both entail liking and devoting a great deal of time 
and energy toward an activity, they differ in the quality of the activity engagement. HP involves pursuing a passionate activity with a sense of control, flexibility, and balance with other life interests, whereas OP involves pursuing a passionate activity with a sense of rigidity and conflict with other pursuits (Vallerand, 2015). Research that has studied the outcomes that are linked with both varieties of passion among athletes has found that, in general, athletes with high levels of HP experience more adaptive outcomes (e.g., greater positive affect, psychological wellbeing, flow), whereas athletes with high levels of OP experience adaptive outcomes to a lesser extent and at times report greater maladaptive outcomes (e.g., greater negative affect, rumination, stress; for reviews, see Curran et al., 2015; Vallerand \& Verner-Filion, 2020; Vallerand, 2015).

Research has also started to study how both passion dimensions relate to how people respond when good things happen in a passionate activity, including the extent to which they engage in savoring. HP is associated with pursuing activities with a greater sense of mindfulness (e.g., St-Louis et al., 2018), a better ability to become fully immersed in an activity and experience flow (e.g., Lavigne et al., 2012), and a positive outlook on the past, present, and future (Vallerand \& St-Louis, in press). All of these features of HP should facilitate greater levels of savoring (Bryant \& Veroff, 2007; Ritchie \& Bryant, 2012). Indeed, research has found support for a positive association between HP and savoring positive experiences (Schellenberg \& Gaudreau, 2020; Schellenberg et al., 2020; Vallerand \& St-Louis, in press). In contrast, the relationship between OP and savoring is less clear. On the one hand, OP is associated with several features that could reduce one's capacity to savor, including conflict between the activity and other life domains (Vallerand et al., 2010), a tendency to ruminate about a passionate activity (Carpentier et al., 2012), and even poor interpersonal relationships (e.g., Philippe et al., 2010). 
These features could make it more difficult to engage in savoring because they prevent one from being mindful and present while engaging in an activity, and also make it more challenging to find others with whom to share positive experiences. On the other hand, positive experiences should be especially significant for people with high OP because their identities are dominated by their passionate activities (e.g., Lafrenière et al., 2012). This means that those with high OP may be particularly inclined to savor positive experiences because they are perceived as being especially important and meaningful. Research on this topic has found that OP predicts lower levels of savoring tendencies (i.e., savoring capacity), but greater savoring when imagining or shortly after experiencing extremely positive events (Schellenberg \& Gaudreau, 2020; Schellenberg et al., 2020). Although research in this area is just beginning, these findings suggest that OP may predict less savoring of more common, everyday positive experiences (e.g., winning a game), but more savoring of less common, exceptional positive experiences (e.g., winning a championship).

Research studying the link between passion and savoring is still in its initial stages and has yet to focus on athletes. Athletes can have so many different types of positive experiences that it would seem that they have many opportunities to engage in savoring. Moreover, given that both HP and OP have been shown to predict how athletes respond to and cope with difficult times (Schellenberg et al., 2013; Verner-Filion et al., 2014), it would seem that both passion types might also predict how athletes respond to good times. In line with the aforementioned research conducted with non-athlete populations, we hypothesized that HP among athletes would be positively associated with savoring (Hypothesis 1). And although theoretical arguments can be made for either a positive or negative link between OP and savoring, in this research we anticipated a negative association between OP and savoring (Hypothesis 2) because we focused 
on general savoring tendencies rather than savoring of exceptionally positive experiences. As we explain, we reasoned that savoring tendencies are most relevant for predicting the development of athlete burnout.

\section{Associations with Athlete Burnout}

Athlete burnout is a syndrome involving feelings of emotional and physical exhaustion, reduced sense of accomplishment, and sport devaluation (Raedeke \& Smith, 2009). Burnout can develop over time and is associated with various maladaptive motivational, emotional, and cognitive consequences (e.g., Eklund \& DeFreese, 2020; Goodger et al., 2007; Gustafsson et al., 2017). Given the intense levels of commitment and desire that passionate athletes have toward their sport, researchers have examined if passionate athletes are prone to experiencing burnout and if their susceptibility to burnout is related to HP and OP. Results with HP have been fairly consistent and have shown that HP predicts lower levels of athlete burnout (Curran et al., 2011, 2013; Gustafsson, Hassmén, \& Hassmén, 2011; Lopes \& Vallerand, 2020; Martin \& Horn, 2013). Result with OP, in contrast, have been more inconsistent and have yielded positive (Gustafsson, Hassmén, \& Hassmén, 2011; Lopes \& Vallerand, 2020; Martin \& Horn, 2013), null (Curran et al., 2011, 2013), and even negative (Schellenberg et al., 2013) associations with burnout. There is therefore a need to better understand the mechanisms through which both passion varieties, especially OP, relate to burnout (Vallerand \& Verner-Filion, 2020). We believe that savoring could represent an additional intervening process in these relationships.

There is reason to suspect that athletes who savor positive experiences are less likely to develop symptoms of burnout. First, the positive emotions that are prolonged and augmented with savoring may undo any after effects resulting from negative emotions (Fredrickson et al., 2000) and enhance the extent to which athletes feel energetic (Lyubomirsky et al., 2005) and 
subjective vitality (Ryan \& Frederick, 1997). As a result, savoring may protect athletes from becoming physically and emotionally exhausted. Second, savoring entails focusing on, attending to, and appreciating all that one is achieving, which may prevent athletes from feeling low levels of accomplishment in sport. Third, by keeping athletes attuned to the positive aspects of sport and all that their sport has to offer, savoring may protect athletes from developing negative attitudes toward their sport and devaluing it. Moreover, burnout is conceptualized as a syndrome that develops over time (Gustafsson et al., 2017), meaning that athletes who tend to savor all types of positive experiences in sport, not just those that are especially positive or rare, may be most protected from experiencing burnout. Preliminary research has supported this reasoning by finding that savoring tendencies are negatively associated with burnout among employees (Sytine, 2019). Research has yet to assess if savoring has any effects on burnout among athletes. We hypothesized that savoring would be negatively associated with all three dimensions of athlete burnout (Hypothesis 3). Moreover, given previous research on the associations between HP, OP, and both savoring and burnout, we expected that savoring would have an indirect effect in the relationship between both passion varieties and burnout (Hypothesis 4).

\section{The Current Research}

The purpose of this research was to test our hypotheses and study the relationships between passion varieties, savoring, and burnout among athletes. We did so in two studies. In Study 1, we tested the relationships between both types of passion, savoring, and burnout symptoms using a cross-sectional design in a heterogeneous sample of athletes competing in various sports at various levels of competition. In Study 2, we replicated Study 1 using a prospective design with college- and university-level athletes over the course of a season. ${ }^{1}$ In

\footnotetext{
${ }^{1}$ Data from each study were collected as part of larger projects that we are currently in the process of preparing for publication. All other reports from these projects focus on different variables and test different hypotheses.
} 
both studies, samples sizes were predetermined as being sufficient to detect medium-sized effects ( $r=.20$; see Funder \& Ozer, 2019) assuming at least $80 \%$ power and $\alpha=.05$. Institutional ethics approval was attained prior to data collection, and each participant provided informed consent. Syntax and anonymous data files for each study are available on the Open Science Framework at https://osf.io/s2j5d/.

\section{Study 1}

\section{Method}

\section{Participants and Procedure}

Participants $(n=499)$ were recruited from either Prolific Academic $(n=442)$ or from undergraduate kinesiology classes $(n=57)$. Prolific users were eligible to participate if they reported on a pre-screening survey that they were over 18 years of age and played a sport on a regular basis. Kinesiology students were eligible to participate if they self-identified as athletes. Additional participants $(n=11)$ completed the study but were excluded from all analyses because they either reported that they were no longer playing a sport on a regular basis $(n=7)$, or reported that they were not honest in their responses $(n=4)$. Participants $(270$ males, 224 females, 5 did not report a gender) ranged from 18 to 69 years old $(M=33.65$ years, $S D=11.74$ years), and most identified having a White/European ethnic background (85.0\%). Participants reported playing their sport for an average of 5.13 hours $(S D=4.10$ hours $)$ per week, and most (63.9\%) identified playing at a moderately competitive level or higher. Participants were compensated with either electronic gift cards (undergraduates) or $£ 2.89$ (Prolific users, approximately $\$ 3.78 \mathrm{USD})$.

\section{Measures}

Passion. Participants answered items from the Passion Scale (Vallerand et al., 2003) to 
assess levels of HP (6 items; e.g., "My sport is in harmony with the other activities in my life") and OP (6 items; e.g., "I have difficulties controlling my urge to play my sport") for playing their sport. Each item was answered on a Likert scale ranging from 1 (not agree at all) to 7 (totally agree). Responses were averaged to create HP $(\omega=.87)$ and $\mathrm{OP}(\omega=.88)$ scores. Previous research has supported the psychometric properties of the Passion Scale in general (Marsh et al., 2013; Vallerand, 2015) and specifically in sport (Schellenberg et al., 2014).

Savoring. After completing the Passion Scale, participants completed the Savoring Beliefs Inventory (SBI; Bryant, 2003; Bryant \& Veroff, 2007) as an assessment of one’s capacity to savor positive experiences. The SBI includes 24 items that assess savoring beliefs at three temporal orientations: savoring the moment $(\omega=.84$; e.g., "I know how to make the most of a good time"), anticipating future positive experiences $(\omega=.77$; e.g., "I feel a joy of anticipation when I think about upcoming good things"), and reminiscing about past positive experiences ( $\omega$ $=.78$; e.g., "I enjoy looking back on happy times from my past"). Participants answered the items while thinking about how they generally feel about positive events that occur while they play their sport. Each item was answered on a Likert scale ranging from 1 (not at all true) to 7 (totally true). In both Studies 1 and 2 we focused on total SBI scores rather than individual SBI subscale scores because (a) our hypotheses pertained to general savoring capacities rather than capacities to savor at different temporal orientations, (b) scores on the three SBI subscales are usually strongly correlated with one another (see Bryant, 2003; Kawakubo et al., 2019; the correlations observed in both studies of the current research ranged from .47 to .71), and (c) it has been suggested that the distinction between temporal orientations may not be as relevant in non-clinical populations (Bryant, 2003). For these reasons, and in line with the majority of 
research using the SBI, items were averaged to create total savoring scores $(\omega=.92){ }^{2}$ Previous validation research has supported the psychometric properties of the SBI (Bryant, 2003;

Kawakubo et al., 2019).

Burnout. Participants completed the 15-item Athlete Burnout Questionnaire (ABQ; Raedeke \& Smith, 2009). On a scale ranging from 1 (almost never) to 5 (almost always), the ABQ assesses the three components of burnout: emotional/physical exhaustion $(\omega=.88$; e.g., "I feel overly tired from my sport participation"), reduced sense of accomplishment $(\omega=.71$; e.g., "I am not achieving much in my sport"), and sport devaluation $(\omega=.76$; e.g., "I'm not into my sport like I used to be"). The ABQ has been used extensively in research with athletes and has received strong psychometric support (see Raedeke \& Smith, 2009).

\section{Data Analysis}

We used SPSS (Version 25) to compute descriptive statistics and correlations, and Mplus (Version 8) test a path model in which HP and OP predicted savoring, which in turn predicted the three burnout dimensions. Fit indices were not available for this model because it was fully saturated (i.e., zero degrees of freedom). All models were tested using robust maximum likelihood estimation (MLR) to account for potential deviations in normality. Indirect effects were tested by interpreting $95 \%$ bias-corrected bootstrapped confidence intervals $(5,000$ samples). Maximum likelihood (ML) estimation was used to compute bootstrapped confidence intervals because bootstrapping is not available in Mplus using MLR. For both studies we

\footnotetext{
${ }^{2}$ We tested the factor structure of the SBI because this is one of the first times it has been administered to athletes in relation to savoring capacity in sport. Following previous validation analyses with the SBI (Bryant, 2003; Kawakubo et al., 2019), we tested a 5-factor model that included three factors representing each SBI subscale (savoring the moment, anticipating, and reminiscing), along with two "method" factors that represented positively- and negatively-anchored items (both method factors were allowed to correlate with each other but not with the other factors). Acceptable indices of fit for this model were obtained in Study 1, MLR $\chi^{2}(224)=439.816, p<.001$, CFI = $.955, \mathrm{TLI}=.945, \mathrm{RMSEA}=.044,90 \% \mathrm{CI}=[.038, .050]$, and Study $2, \mathrm{MLR} \chi^{2}(224)=326.309, p<.001, \mathrm{CFI}=$ $.922, \mathrm{TLI}=.904, \mathrm{RMSEA}=.060,90 \% \mathrm{CI}=[.045, .073]$.
} 
interpreted and report standardized coefficients (using the STDYX option in Mplus). ${ }^{3}$

\section{Results and Brief Discussion}

Descriptive statistics and correlations are displayed in Table 1, and results from the path analysis are displayed in Figure 1. Savoring was positively predicted by $\mathrm{HP}(\beta=.371, p<.001)$, and negatively predicted by OP $(\beta=-.300, p<.001)$. Savoring, in turn, was negatively related to emotional/physical exhaustion $(\beta=-.229, p<.001)$, reduced sense of accomplishment $(\beta=-$ $.245, p<.001)$, and sport devaluation $(\beta=-.195, p<.001)$. As shown in Table 2 , there was evidence of a significant indirect effect of savoring in the relationship between each passion type and each burnout dimension.

The results supported Hypotheses 1 and 2 by showing that savoring was positively associated with HP but negatively associated with OP. The results also revealed negative associations between savoring and each burnout dimension (supporting Hypothesis 3), and that savoring played an indirect role in the associations between both passion dimensions and burnout (supporting Hypothesis 4). This suggests that athletes who tend to savor positive moments in sport also experience lower burnout, and that athletes with high HP may be most likely to savor. But these results were obtained from a sample that included many athletes $(36.1 \%)$ who reported playing a sport at a level that was not particularly competitive, and who therefore may not have been at a high risk of experiencing burnout. Moreover, the results were based on cross-sectional data, which can introduce bias when assessing indirect effects (Maxwell \& Cole, 2007).

Therefore, in Study 2 we replicated these effects prospectively over the course of a season in a sample of athletes who all played at a highly-competitive level.

\footnotetext{
${ }^{3}$ In both studies, we checked for the potential influence of outliers by visually inspecting Mahalanobis distance scores and re-analyzing path models with potential outliers removed. Three potential outliers were identified in each study. Removing potential outlying cases did not affect the results in any substantial way. We therefore report analyses that include all cases.
} 


\section{Study 2}

\section{Method}

\section{Participants and Procedure}

Athletes $(n=298)$ were participants in the Student-athlete Well-being and Achievement Study (SWAP), a prospective study designed to explore relationships between student-athlete motivation and experiences throughout an academic year. Athletes who competed for colleges and universities in Winnipeg, Manitoba were invited to participate. Athletes eligible for the SWAP were those who competed in basketball (81 athletes from 6 teams), hockey (48 athletes from 2 teams), track/field (46 athletes from 1 team), or volleyball (123 athletes from 10 teams) because the competitive seasons for these sports roughly aligned with the post-secondary academic year. ${ }^{4}$ Participants (167 males, 131 females) ranged from 17 to 35 years old $(M=$ 20.12 years, $S D=2.48$ years), and most identified having a White/European ethnic background (62.1\%). Participants reported playing their sport for an average of 16.35 hours $(S D=7.15$ hours) per week, and most were either in their first (38.6\%), second (16.1\%), or third (20.8\%) year of eligibility. Participants were compensated with \$5 CAD in cash at Time 1, and with a contribution toward an electronic gift card for each online survey that they completed at Times 2 and 3 .

At the beginning of the academic year in the pre-season phase of the competitive season (September-October, 2019), the first author contacted coaches of teams competing in the Winnipeg area to explain the study and ask for their assistance in organizing a time to meet with their teams. The first author and a research assistant then met with interested teams to invite athletes to participate. Those who agreed to participate then completed the first survey (Time 1)

\footnotetext{
${ }^{4}$ Athletes competing in track/field were all considered to come from the same team because they all competed for the same university and trained together with the same group of coaches.
} 
of the SWAP. As part of the survey administered at Time 1, participants were asked to provide their email addresses, which we used distribute electronic surveys after the first term of the academic year in the middle of the competitive season (Time 2; December, 2019), and in the middle of the second academic term near the end of the competitive season (Time 3, February, 2020). Variables were assessed at these measurement points because they were natural phases of the competitive season and academic year and had a sufficient temporal separation between them to assess prospective relationships and control for method biases (Podsakoff et al., 2012). Participants provided informed consent as part of each survey, and ethics approval was obtained from each academic institution (5 in total) where athletes were recruited at Time 1.

\section{Measures}

Participants completed the same measures of passion, savoring, and burnout that were assessed in Study 1. At Time 1, participants completed the Passion Scale while thinking of their sport. Responses were averaged to created HP $(\omega=.80)$ and OP $(\omega=.80)$ scores. At Time 2, participants completed the SBI while thinking of how they feel about positive events that occur in their sport. SBI responses were averaged to create total savoring scores $(\omega=.87)$. Finally, at Time 3, participants completed the ABQ to assess levels of emotional/physical exhaustion $(\omega=$ $.91)$, reduced sense of accomplishment $(\omega=.86)$, and sport devaluation $(\omega=.87)$.

\section{Data Analysis}

Using the same procedures described in the analysis of Study 1, we tested a path model in which HP and OP (assessed at Time 1) predicted savoring capacity (assessed at Time 2), which in turn predicted the three burnout dimensions (assessed at Time 3). Like in Study 1, fit indices were not available because the model was fully saturated. We accounted for the nested structure of the data (i.e., 298 athletes nested within 19 teams) by adjusting the standard errors using the 
TYPE $=$ COMPLEX command in Mplus. ${ }^{5}$ Prior to testing this model, we conducted attrition analyses to determine the percentage of participants who completed each time point, and tested if those who did and did not complete all three time points differed from each other in any systematic way. Of the 298 athletes who completed Time 1, 132 athletes (44.3\%) completed Time 2, and 103 athletes (34.6\%) completed Time 3. Those who did and did not complete all three time points did not differ from each other on the variables assessed at Time 1, including levels of HP, OP, hours spent training per week, age, or current year of eligibility. We also found that we could not reject the hypothesis that the missing data from the variables specified in the path model were not missing completely at random (MCAR), Little's MCAR $\chi^{2}(10)=11.53, p$ $=.318$. We therefore modeled observed covariate missingness using procedures outlined by Muthén and Muthén (1998-2017, p. 8), and managed missing data using full information maximum likelihood (FIML), the default procedure in Mplus.

\section{Results and Brief Discussion}

Descriptive statistics and correlations were computed in Mplus using FIML (see Table 1). Results from the path analysis are displayed in Figure 1. Savoring was positively predicted by $\mathrm{HP}(\beta=.492, p<.001)$, and negatively predicted by OP $(\beta=-.317, p<.001)$. Savoring, in turn, was negatively related to reduced accomplishment $(\beta=-.215, p=.032)$ and sport devaluation $(\beta$ $=-.313, p=.007)$. Savoring was not significantly associated with emotional/physical exhaustion $(\beta=-.149, p=.315)$. As shown in Table 2 , there was evidence of a significant indirect effect of savoring in the relationship between each passion types and both sport devaluation and reduced accomplishment.

\footnotetext{
5 This model had more parameters than clusters, which caused a message to be displayed in our output warning that the standard errors may not be trustworthy. To test the impact of the TYPE = COMPLEX adjustment on the standard errors, we ran an additional model that did not adjust for the nested data structure. The results of this model did not differ in any substantial way from the model that accounted for the nested data structure.
} 
These results replicated the results from Study 1 by again showing that savoring was positively associated with HP (supporting Hypothesis 1) and negatively associated with OP (supporting Hypothesis 2). The results partially supported Hypotheses 3 by showing that savoring, assessed mid-season, predicted lower levels of reduced accomplishment and sport devaluation at the end of the season. Savoring did not significantly predict emotional/physical exhaustion, although the effect was in the hypothesized direction. But with the exception of emotional/physical exhaustion, these results replicate the effects observed from Study 1 in a sample of highly-competitive athletes using a prospective study spanning over the course of an entire season.

\section{General Discussion}

Athletes can experience all types of positive moments while playing their sport. In this research, we assessed the extent to which athletes respond during these good times by engaging in savoring - that is, by attempting to prolong or amplify their positive emotions (Bryant \& Veroff, 2007). Consistent across both studies, we found that HP was associated with a greater tendency to savor positive events, and that savoring, in turn, was negatively linked with symptoms of burnout. These findings have implications for research and applied practice related to savoring, passion, and burnout in sport.

\section{Savoring Sport}

Research outside of sport has shown that savoring is an adaptive response to positive experiences that predicts various positive outcomes including greater happiness and overall wellbeing, and fewer symptoms of depression and negative feelings (e.g., Hurley \& Kwon, 2012, 2013; Wilson et al., 2020). Research is now starting to emerge that shows that athletes can also benefit from savoring positive experiences (Doorley \& Kashdan, 2021). The current research 
increased our understanding of savoring in sport in at least two ways. First, it showed that the benefits of savoring for athletes may extend to perceptions of burnout. Specifically, savoring can allow athletes to enhance or prolong the positive emotions that result from positive experiences in sport, and to pay attention to and appreciate their accomplishments and all their sport has to offer. This means that savoring may prevent athletes from experiencing all three dimensions of burnout, including feelings of emotional and physical exhaustion, low accomplishment, and negative attitudes toward sport. In line with this reasoning, both studies showed that savoring predicted lower levels of reduced accomplishment and sport devaluation. The negative association between savoring and emotional/physical exhaustion, however, was found only in Study 1 . This inconsistency between Studies 1 and 2 could be explained by differences in terms of the study design (cross-sectional vs. prospective) or population (athletes from all levels vs. athletes competing in competitive post-secondary leagues). Another explanation may be that savoring has a stronger effect on burnout dimensions related to attitudes (i.e., perceptions of accomplishment and sport value), rather than feelings of exhaustion. This may be a critical point because exhaustion is generally considered to be the core component of burnout (Maslach et al., 2001; Schaufeli \& Buunk, 2003). Although the relationship between savoring and emotional/physical exhaustion in Study 2 was in the hypothesized direction, more research is needed to determine if savoring is related to some burnout dimensions more than others.

Second, this research showed that not all athletes savor to the same extent. Building on research studying how passionate individuals cope with and regulate their negative emotional experiences (e.g., St-Louis et al., 2020), this research showed that passion also matters when predicting how athletes regulate their positive emotional experiences during good times. Consistent across both studies, and consistent with research conducted with non-athlete 
populations (e.g., Schellenberg et al., 2020), HP was positively associated with savoring. This finding supports the theoretical position that HP should facilitate savoring because it entails engaging in an activity with a positive perspective, a better ability to become immersed in one's surroundings and experience flow, and a sense of mindfulness (Vallerand, 2015). OP, in contrast, predicted lower levels of general savoring tendencies. Although theoretical arguments can be made for either positive or negative associations with savoring, this research along with previous research (Schellenberg \& Gaudreau, 2020) supports a negative association between OP and savoring tendencies. However, past research examining savoring after specific positive events, such as team championships, has found positive associations between OP and savoring (Schellenberg et al., 2020). This supports the view that OP predicts a greater tendency to engage in savoring following extremely positive but rare events, and a lower tendency to engage in dayto-day savoring of more common positive events. Additional research relying on an experimental design is needed to provide stronger support for the potential moderating effects of event positivity and frequency on the relationship between OP and savoring.

\section{Do Athletes Burn Out from Passion?}

Passionate athletes love to play their sport, spend a great deal of their time and energy doing so, and have incorporated being an athlete into their self-concepts. Researchers have thus been fascinated by the question of whether athletes with this type of intense motivation experience higher levels of burnout (Gustafsson, Hassmén, \& Hassmén, 2011). Research on this topic has found that it is critical to consider the type of passion one has for sport, with HP being consistently linked with lower levels of burnout, and OP showing less consistent links with burnout (Vallerand \& Verner-Filion, 2020). In this research, the total effects observed in each study supported the protective effect of HP in the development of burnout, but found that OP 
was either positively (Study 1) or unrelated (Study 2) to burnout. Once again, differences in study designs and samples might be one explanation for these discrepancies. However, previous research has identified several processes through which both HP and OP relate to athlete burnout, including psychological need satisfaction (Curran et al., 2013; Lopes \& Vallerand, 2020), self-determined motivation (Curran et al., 2011), conflict with other life domains (Lopes \& Vallerand, 2020), and coping (Schellenberg et al., 2013). This research has shown that HP predicts processes that generally protect individuals from burnout (e.g., greater use of taskoriented coping, higher levels of psychological need satisfaction and self-determined motivation), whereas OP predicts processes that are related to greater burnout (e.g., greater use of disengagement-oriented coping, more life conflict). The current research contributes to our understanding of the link between both passion types and athlete burnout by showing that savoring is an additional intervening process through which both passion types relate to burnout.

\section{Clinical Implications}

The findings of this research have potential implications for clinicians and for applied practice in sport. This research contributes to the literature on athlete burnout interventions (e.g., Dubuc-Charbonneau \& Durand-Bush, 2015; Gabana et al., 2019) by identifying savoring as an additional emotion regulation strategy that may protect athletes from experiencing burnout. Many different interventions have been developed to enhance savoring (for a review, see Smith et al., 2014), most of which are fairly brief and involve writing and thinking activities designed to enhance people's appreciation of past, present, and future positive experiences (e.g., Hurley \& Kwon, 2012; Lyubomirsky et al., 2006; Smith \& Hanni, 2019). These types of savoring interventions, on average, have a small but significant effect on outcomes such as happiness and positive affect (Smith et al., 2014). Athletes may profit from similar types of brief interventions 
designed to help them make the most of positive experiences that have already taken place (i.e., reminiscing), that they are currently experiencing (i.e., savoring the moment), and that they expect to experience in the future (i.e., anticipating). Based on past savoring research (e.g., Doorley \& Kashdan, 2021; Sytine et al., 2018), such savoring interventions could enhance athlete well-being by both enhancing ongoing positive emotional experiences, and by buffering the impact of negative events on negative emotional reactions. However, we should emphasize that research on savoring behavior among athletes is in its infancy. Continued research in this area is needed to enhance our understanding of the potential impact that these types of savoring interventions might have with athletes.

In addition, this research found that athletes with low HP, and perhaps also athletes with high OP, are at risk of experiencing higher levels of burnout. This finding, along with what we already know about HP in sport (Vallerand \& Verner-Filion, 2020), suggests that applied practitioners should promote and encourage athletes to become highly harmoniously passionate for their sport. Research relying on the dualistic model of passion has identified several personal and social factors that contribute to higher HP, including having an autonomous personality orientation, having high levels of self-oriented perfectionism, receiving autonomy support from others, being led by one who adopts a transformational style of leadership, and engaging in an environment that allows one to use their signature strengths (see Vallerand, 2015). Targeting these factors aligns with the broad recommendation to focus on both the athlete and the athlete's environment when designing interventions to enhance athlete well-being (Eklund \& DeFreese, $2015 ; 2020)$.

\section{Limitations and Future Directions}

This research is limited by its reliance on self-report measures and, although Study 2 
adopted a prospective design over the course of a competitive season, the use of cross-sectional methods in Study 1. The results should be viewed as being consistent with the hypothesis that specific passion types influence different levels of savoring, which in turn influence rates of burnout; however, the results do not directly provide causal evidence. And although savoring was found to be prospectively related to burnout, we cannot rule out the possibility of a reciprocal pattern in which burnout leads to lower savoring. Causality can be tested using interventions that have been shown to effectively manipulate passion types (see Vallerand, 2015) and savoring behaviour (see Smith et al., 2014). Adopting such designs with athletes is an important direction for future research.

This research exposes several questions that need to be addressed, including questions concerning when OP predicts more or less savoring responses, and if savoring is best viewed as a process that protects athletes from experiencing dimensions of burnout related to negative attitudes. Research is also needed to understand the mechanisms that could explain why savoring predicts lower burnout. One possibility is that savoring helps athletes cope with and/or avoid the accumulation of chronic stress (Sytine et al., 2019; Wilson et al., 2020), which is recognized as being a key factor in the development of athlete burnout (e.g., Gustafsson, Kenttä, \& Hassmén, 2011; Smith, 1986). Savoring could also have an impact on other outcomes among athletes, including psychological well-being, mental health, and perhaps even team cohesion and sport performance. Moreover, the advantages of savoring likely extend to other types of sport participants. Coaches, referees, parents, and volunteers who savor may, in turn, experience benefits to their sense of well-being and their overall experience in sport.

\section{Conclusion}

This research showed that HP among athletes was positively associated with savoring, 
and that savoring was negatively associated with symptoms of athlete burnout. These results mean that passionate athletes with a harmonious relationship with sport are most likely to respond to good times by attempting to enhance or prolong their positive feelings, and that doing so may protect them from becoming emotionally or physical exhausted, feeling a reduced sense of accomplishment, and developing negative attitudes toward their sport. Savoring thus appears to be an adaptive way of responding to positive experiences in sport, a finding that is in line with recent findings with athletes (Doorley \& Kashdan, 2021) and with research conducted in nonathlete populations (e.g., Wilson et al., 2020). Research on savoring in sport is just beginning, and more research in this area is needed to help learn more about the antecedents and outcomes of savoring for all types of sport participants. 


\section{References}

Bryant, F. (2003). Savoring Beliefs Inventory (SBI): A scale for measuring beliefs about savouring. Journal of Mental Health, 12(2), 175-196. https://doi.org/fkxbg3

Bryant, F. B., \& Veroff, J. (2007). Savoring: A new model of positive experience. Lawrence Erlbaum Associates.

Carpentier, J., Mageau, G. A., \& Vallerand, R. J. (2012). Ruminations and flow: Why do people with a more harmonious passion experience higher well-being? Journal of Happiness Studies, 13(3), 501-518. https://doi.org/10.1007/s10902-011-9276-4

Curran, T., Appleton, P. R., Hill, A. P., \& Hall, H. K. (2011). Passion and burnout in elite junior soccer players: The mediating role of self-determined motivation. Psychology of Sport and Exercise, 12(6), 655-661. https://doi.org/10.1016/j.psychsport.2011.06.004

Curran, T., Appleton, P. R., Hill, A. P., \& Hall, H. K. (2013). The mediating role of psychological need satisfaction in relationships between types of passion for sport and athlete burnout. Journal of Sports Sciences, 31(6), 597-606. https://doi.org/fbsk

Curran, T., Hill, A. P., Appleton, P. R., Vallerand, R. J., \& Standage, M. (2015). The psychology of passion: A meta-analytical review of a decade of research on intrapersonal outcomes. Motivation and Emotion, 39(5), 631-655. https://doi.org/10.1007/s11031-015-9503-0

Doorley, J. D., \& Kashdan, T. B. (2021). Positive and negative emotion regulation in college athletes: A preliminary exploration of daily savoring, acceptance, and cognitive reappraisal. Cognitive Therapy and Research. https://doi.org/10.1007/s10608-020-10202-4

Dubuc-Charbonneau, N., \& Durand-Bush, N. (2015). Moving to action: The effects of a selfregulation intervention on the stress, burnout, well-being, and self-regulation capacity levels of university student-athletes. Journal of Clinical Sport Psychology, 9(2), 173-192. 
https://doi.org/10.1123/jcsp.2014-0036

Eklund, R. C., \& DeFreese, J. D. (2020). Athlete burnout. In G. Tenenbaum \& R. C. Eklund (Eds.), Handbook of Sport Psychology (4 ${ }^{\text {th }}$ ed., pp. 1220-1240). Wiley.

Eklund, R. C., \& DeFreese, J. D. (2015). Athlete burnout: What we know, what we could know, and how we can find out more. International Journal of Applied Sports Sciences, 27(2), 6375. https://doi.org/10.24985/IJASS.2015.27.2.63

Fredrickson, B. L., Mancuso, R. A., Branigan, C., \& Tugade, M. M. (2000). The undoing effect of positive emotions. Motivation and Emotion, 24(4), 237-258. https://doi.org/b8xx5p

Funder, D. C., \& Ozer, D. J. (2019). Evaluating effect size in psychological research: Sense and nonsense. Advances in Methods and Practices in Psychological Science, 2(2), 156-168. https://doi.org/10.1177/2515245919847202

Gabana, N. T., Steinfeldt, J., Wong, Y. J., Chung, Y. B., \& Svetina, D. (2019). Attitude of gratitude: Exploring the implementation of a gratitude intervention with college athletes. Journal of Applied Sport Psychology, 31(3), 273-284. https://doi.org/fwhn

Goodger, K., Gorely, T., Lavallee, D., \& Harwood, C. (2007). Burnout in sport: A systematic review. The Sport Psychologist, 21(2), 127-151. https://doi.org/10.1123/tsp.21.2.127

Gustafsson, H., DeFreese, J., \& Madigan, D. J. (2017). Athlete burnout: Review and recommendations. Current Opinion in Psychology, 16, 109-113. https://doi.org/gcz9r3

Gustafsson, H., Hassmén, P., \& Hassmén, N. (2011). Are athletes burning out with passion? European Journal of Sport Science, 11(6), 387-395. https://doi.org/dvq5qf

Gustafsson, H., Kenttä, G., \& Hassmén, P. (2011). Athlete burnout: An integrated model and future research directions. International Review of Sport and Exercise Psychology, 4(1), 324. https://doi.org/10.1080/1750984X.2010.541927 
Hurley, D. B., \& Kwon, P. (2012). Results of a study to increase savoring the moment:

Differential impact on positive and negative outcomes. Journal of Happiness Studies, 13(4), 579-588. https://doi.org/10.1007/s10902-011-9280-8

Hurley, D. B., \& Kwon, P. (2013). Savoring helps most when you have little: Interaction between savoring the moment and uplifts on positive affect and satisfaction with life. Journal of Happiness Studies, 14(4), 1261-1271. https://doi.org/fbsm

Jose, P. E., Lim, B. T., \& Bryant, F. B. (2012). Does savoring increase happiness? A daily diary study. The Journal of Positive Psychology, 7(3), 176-187. https://doi.org/gghxfm

Kawakubo, A., Bryant, F. B., Miyakawa, E., \& Oguchi, T. (2019). Development and validation of the Japanese version of the Savoring Beliefs Inventory (SBI-J). Journal of Positive School Psychology, 3(2), 119-136.

Lafrenière, M.-A. K., St-Louis, A. C., Vallerand, R. J., \& Donahue, E. G. (2012). On the relation between performance and life satisfaction: The moderating role of passion. Self and Identity, 11(4), 516-530. https://doi.org/10.1080/15298868.2011.616000

Lavigne, G. L., Forest, J., \& Crevier-Braud, L. (2012). Passion at work and burnout: A two-study test of the mediating role of flow experiences. European Journal of Work and Organizational Psychology, 21(4), 518-546. https://doi.org/ck5q25

Lopes, M., \& Vallerand, R. J. (2020). The role of passion, need satisfaction, and conflict in athletes' perceptions of burnout. Psychology of Sport and Exercise, 48, 101674. https://doi.org/10.1016/j.psychsport.2020.101674

Lyubomirsky, S., King, L., \& Diener, E. (2005). The benefits of frequent positive affect: Does happiness lead to success? Psychological Bulletin, 131(6), 803-855. https://doi.org/bcnt2d Lyubomirsky, S., Sousa, L., \& Dickerhoof, R. (2006). The costs and benefits of writing, talking, 
and thinking about life's triumphs and defeats. Journal of Personality and Social Psychology, 90(4), 692-708. https://doi.org/10.1037/0022-3514.90.4.692

Marsh, H. W., Vallerand, R. J., Lafrenière, M.-A. K., Parker, P., Morin, A. J. S., Carbonneau, N., Jowett, S., Bureau, J. S., Fernet, C., Guay, F., Salah Abduljabbar, A., \& Paquet, Y. (2013). Passion: Does one scale fit all? Construct validity of two-factor passion scale and psychometric invariance over different activities and languages. Psychological Assessment, 25, 796-809. https://doi.org/fp69

Martin, E. M., \& Horn, T. S. (2013). The role of athletic identity and passion in predicting burnout in adolescent female athletes. The Sport Psychologist, 27(4), 338-348. https://doi.org/10.1123/tsp.27.4.338

Maslach, C., Schaufeli, W. B., \& Leiter, M. P. (2001). Job burnout. Annual Review of Psychology, 52(1), 397-422. https://doi.org/10.1146/annurev.psych.52.1.397

Maxwell, S. E., \& Cole, D. A. (2007). Bias in cross-sectional analyses of longitudinal mediation. Psychological Methods, 12(1), 23-44. https://doi.org/10.1037/1082-989X.12.1.23

Muthén, L. K., \& Muthén, B. O. (1998-2017). Mplus user’s guide (8th ed.). Muthén \& Muthén Philippe, F. L., Vallerand, R. J., Houlfort, N., Lavigne, G. L., \& Donahue, E. G. (2010). Passion for an activity and quality of interpersonal relationships: The mediating role of emotions. Journal of Personality and Social Psychology, 98(6), 917-932. https://doi.org/ctrwj9

Podsakoff, P. M., MacKenzie, S. B., \& Podsakoff, N. P. (2012). Sources of method bias in social science research and recommendations on how to control it. Annual Review of Psychology, 63(1), 539-569. https://doi.org/10.1146/annurev-psych-120710-100452

Raedeke, T. D., \& Smith, A. L. (2009). The athlete burnout questionnaire manual. Fitness Information Technology. 
Ritchie, T. D., \& Bryant, F. B. (2012). Positive state mindfulness: A multidimensional model of mindfulness in relation to positive experience. International Journal of Wellbeing, 2(3), 150-181. https://doi.org/10.5502/ijw.v2.i3.1

Ryan, R. M., \& Frederick, C. (1997). On energy, personality, and health: Subjective vitality as a dynamic reflection of well-being. Journal of Personality, 65(3), 529-565. https://doi.org/fdc3fx

Schall, M., Goetz, T., Martiny, S. E., \& Hall, N. C. (2017). It ain't over 'til it's over: The effect of task completion on the savoring of success. Motivation and Emotion, 41(1), 38-50. https://doi.org/10.1007/s11031-016-9591-5

Schaufeli, W. B., \& Buunk, B. P. (2003). Burnout: An overview of 25 years of research and theorizing. In M. J. Schabracq, J. A. M. Winnubst, \& C. L. Cooper (Eds.), The Handbook of Work and Health Psychology (pp. 383-425). John Wiley \& Sons, Ltd. https://doi.org/10.1002/0470013400.ch19

Schellenberg, B. J. I., \& Gaudreau, P. (2020). Savoring and dampening with passion: How passionate people respond when good things happen. Journal of Happiness Studies, 21(3), 921-941. https://doi.org/10.1007/s10902-019-00114-w

Schellenberg, B. J. I., Gaudreau, P., \& Crocker, P. R. E. (2013). Passion and coping: Relationships with changes in burnout and goal attainment in collegiate volleyball players. Journal of Sport and Exercise Psychology, 35(3), 270-280. https://doi.org/f45tmv

Schellenberg, B. J. I., Gunnell, K. E., Mosewich, A. D., \& Bailis, D. S. (2014). Measurement invariance of the Passion Scale across three samples: An ESEM approach. Measurement in Physical Education and Exercise Science, 18, 242-258. https://doi.org/f7tv

Schellenberg, B. J. I., Verner-Filion, J., \& Gaudreau, P. (2020). We are the champions, but how 
do we respond? Savoring and dampening in response to championship victories among passionate sports fans. Journal of Sport and Exercise Psychology, 42(3), 261-264. https://doi.org/10.1123/jsep.2019-0271

Smith, R. E. (1986). Toward a cognitive-affective model of athletic burnout. Journal of Sport Psychology, 8, 36-50.

Smith, J. L., \& Hanni, A. A. (2019). Effects of a savoring intervention on resilience and wellbeing of older adults. Journal of Applied Gerontology, 38(1), 137-152. https://doi.org/10.1177/0733464817693375

Smith, J. L., Harrison, P. R., Kurtz, J. L., \& Bryant, F. B. (2014). Nurturing the capacity to savor: Interventions to enhance the enjoyment of positive experiences. In A. C. Parks \& S. M. Schueller (Eds.), The Wiley Blackwell handbook of positive psychological interventions (pp. 42-65). Wiley \& Sons. https://doi.org/fbss

St-Louis, A. C., Rapaport, M., Chénard Poirier, L., Vallerand, R. J., \& Dandeneau, S. (2020). On emotion regulation strategies and well-being: The role of passion. Journal of Happiness Studies. https://doi.org/10.1007/s10902-020-00296-8

St-Louis, A. C., Verner-Filion, J., Bergeron, C. M., \& Vallerand, R. J. (2018). Passion and mindfulness: Accessing adaptive self-processes. The Journal of Positive Psychology, 13(2), 155-164. https://doi.org/10.1080/17439760.2016.1245771

Sytine, A. (2019). The role of savoring positive experiences when faced with challenge and hindrance demands: A longitudinal study. [Unpublished doctoral dissertation]. Clemson University.

Sytine, A. I., Britt, T. W., Pury, C. L. S., \& Rosopa, P. J. (2018). Savouring as a moderator of the combat exposure-mental health symptoms relationship. Stress and Health, 34(4), 582-588. 
https://doi.org/10.1002/smi.2822

Sytine, A. I., Britt, T. W., Sawhney, G., Wilson, C. A., \& Keith, M. (2019). Savoring as a moderator of the daily demands and psychological capital relationship: A daily diary study. The Journal of Positive Psychology, 14(5), 641-648. https://doi.org/10.1080/17439760.2018.1519590

Vallerand, R. J. (2015). The psychology of passion: A dualistic model. Oxford University Press. Vallerand, R. J., Blanchard, C., Mageau, G. A., Koestner, R., Ratelle, C., Léonard, M., Gagné, M., \& Marsolais, J. (2003). Les passions de l'âme: On obsessive and harmonious passion. Journal of Personality and Social Psychology, 85(4), 756-767. https://doi.org/d8gw7m

Vallerand, R. J., Paquet, Y., Philippe, F. L., \& Charest, J. (2010). On the role of passion for work in burnout: A process model. Journal of Personality, 78(1), 289-312. https://doi.org/cs7m22

Vallerand, R. J., \& St-Louis, A. C. (in press). The role of passion in integrated temporal positivity: Implications for optimal functioning. In F. Grouzet (Ed.), The Oxford Handbook of Psychology of Time Travel and Temporality. Oxford University Press.

Vallerand, R.J., \& Verner-Filion, J. (2020). Theory and research in passion for sport and exercise. In G. Tenenbaum \& R. C. Eklund (Eds.), Handbook of sport psychology (4 ${ }^{\text {th }}$ ed., pp. 206-229). Wiley \& Sons. https://doi.org/10.1002/9781119568124.ch11

Verner-Filion, J., Vallerand, R.J., Donahue, É.G., Moreau, É., Martin, A., \& Mageau, G.A. (2014). Passion, coping and anxiety in sport: The interplay between key motivational and self-regulatory processes. International Journal of Sport Psychology, 45, 516-537.

Wilson, C. A., \& Saklofske, D. H. (2018). The relationship between trait emotional intelligence, resiliency, and mental health in older adults: The mediating role of savouring. Aging \& Mental Health, 22(5), 646-654. https://doi.org/10.1080/13607863.2017.1292207 
Wilson, J. M., Weiss, A., \& Shook, N. J. (2020). Mindfulness, self-compassion, and savoring: Factors that explain the relation between perceived social support and well-being. Personality and Individual Differences, 152, 109568. https://doi.org/fbsn

Wood, J. V., Heimpel, S. A., \& Michela, J. L. (2003). Savoring versus dampening: Self-esteem differences in regulating positive affect. Journal of Personality and Social Psychology, 85(3), 566-580. https://doi.org/10.1037/0022-3514.85.3.566 


\section{Table 1}

Studies 1 and 2: Descriptive statistics and correlations

\begin{tabular}{|c|c|c|c|c|c|c|c|c|c|c|}
\hline & \multicolumn{2}{|c|}{ Study 1} & \multicolumn{2}{|c|}{ Study 2} & \multirow[b]{2}{*}{1} & \multirow[b]{2}{*}{2} & \multirow[b]{2}{*}{3} & \multirow[b]{2}{*}{4} & \multirow[b]{2}{*}{5} & \multirow[b]{2}{*}{6} \\
\hline & $M$ & $S D$ & $M$ & $S D$ & & & & & & \\
\hline 1. Harmonious Passion & 4.60 & 1.19 & 5.11 & 0.89 & & $.464^{* * *}$ & $.232^{* *}$ & -.004 & $-.428^{* *}$ & $-.216^{* *}$ \\
\hline 2. Obsessive Passion & 2.54 & 1.33 & 3.24 & 1.19 & $.386^{* *}$ & & $-.127^{* *}$ & $.339^{* *}$ & -.070 & .045 \\
\hline 3. Savoring Capacity & 5.05 & 0.88 & 4.87 & 0.72 & $.369^{* *}$ & -.127 & & $-.303^{* *}$ & $-.352^{* *}$ & $-.265^{* *}$ \\
\hline 4. Emotional/Physical Exhaustion & 2.12 & 0.80 & 2.89 & 0.79 & .071 & .027 & -.089 & & $.249^{* *}$ & $.448^{* *}$ \\
\hline 5. Reduced Accomplishment & 2.52 & 0.67 & 2.75 & 0.72 & $-.293^{* *}$ & .016 & $-.317^{* *}$ & $.271^{* *}$ & & $.562^{* *}$ \\
\hline 6. Sport Devaluation & 2.17 & 0.74 & 2.34 & 0.80 & $-.219^{*}$ & -.031 & $-.341^{* *}$ & $.431^{* *}$ & $.591^{* * *}$ & \\
\hline
\end{tabular}

Note. Correlations are displayed for Study 1 (above the diagonal) and Study 2 (below the diagonal). * $p \leq .05 * * p \leq .01$ 
Table 2

Studies 1 and 2: Direct and Indirect Effects

\begin{tabular}{|c|c|c|c|c|c|c|}
\hline & \multicolumn{3}{|c|}{ Study 1} & \multicolumn{3}{|c|}{ Study 2} \\
\hline & Total & Direct & Indirect & Total & Direct & Indirect \\
\hline $\mathrm{HP} \rightarrow \mathrm{SAV} \rightarrow \mathrm{EXH}$ & $\begin{array}{c}-.205^{* *} \\
{[-.295,-.110]}\end{array}$ & $\begin{array}{c}-.120 * \\
{[-.214,-.023]}\end{array}$ & $\begin{array}{c}-.085^{* *} \\
{[-.127,-.053]}\end{array}$ & $\begin{array}{c}.071 \\
{[-.161, .309]}\end{array}$ & $\begin{array}{c}.144 \\
{[-.067, .415]}\end{array}$ & $\begin{array}{c}-.073 \\
{[-.259, .068]}\end{array}$ \\
\hline $\mathrm{HP} \rightarrow \mathrm{SAV} \rightarrow \mathrm{RA}$ & $\begin{array}{c}-.504 * * \\
{[-.583,-.481]}\end{array}$ & $\begin{array}{c}-.413 * * \\
{[-.496,-.323]}\end{array}$ & $\begin{array}{c}-.091 * * \\
{[-.133,-.057]}\end{array}$ & $\begin{array}{c}-.351 * * \\
{[-.515,-.162]}\end{array}$ & $\begin{array}{c}-.246 * * \\
{[-.401,-.092]}\end{array}$ & $\begin{array}{c}-.106 \\
{[-.256,-.004]}\end{array}$ \\
\hline $\mathrm{HP} \rightarrow \mathrm{SAV} \rightarrow \mathrm{DEVAL}$ & $\begin{array}{c}-.301 * * \\
{[-.395,-.201]}\end{array}$ & $\begin{array}{c}-.229 * * \\
{[-.331,-.125]}\end{array}$ & $\begin{array}{c}-.073 * * \\
{[-.115,-.040]}\end{array}$ & $\begin{array}{c}-.244^{*} \\
{[-.468,-.008]}\end{array}$ & $\begin{array}{c}-.090 \\
{[-.278, .122]}\end{array}$ & $\begin{array}{c}-.154^{*} \\
{[-.333,-.034]}\end{array}$ \\
\hline $\mathrm{OP} \rightarrow \mathrm{SAV} \rightarrow \mathrm{EXH}$ & $\begin{array}{c}.434 * * \\
{[.343, .517]}\end{array}$ & $\begin{array}{c}.365 * * \\
{[.270, .450]}\end{array}$ & $\begin{array}{c}.069 * * \\
{[.040, .106]}\end{array}$ & $\begin{array}{c}-.001 \\
{[-.199, .205]}\end{array}$ & $\begin{array}{c}-.048 \\
{[-.265, .220]}\end{array}$ & $\begin{array}{c}.047 \\
{[-.049, .143]}\end{array}$ \\
\hline $\mathrm{OP} \rightarrow \mathrm{SAV} \rightarrow \mathrm{RA}$ & $\begin{array}{c}.164 * * \\
{[.070, .254]}\end{array}$ & $\begin{array}{c}.090 \\
{[-.002, .185]}\end{array}$ & $\begin{array}{c}.074 * * \\
{[.044, .112]}\end{array}$ & $\begin{array}{c}.151 \\
{[-.084, .373]}\end{array}$ & $\begin{array}{c}.083 \\
{[-.163, .301]}\end{array}$ & $\begin{array}{c}.068 * \\
{[.014, .145]}\end{array}$ \\
\hline $\mathrm{OP} \rightarrow \mathrm{SAV} \rightarrow \mathrm{DEVAL}$ & $\begin{array}{c}.185^{* *} \\
{[.084, .281]} \\
\end{array}$ & $\begin{array}{c}.126^{*} \\
{[.026, .221]}\end{array}$ & $\begin{array}{c}.059 * * \\
{[.030, .098]} \\
\end{array}$ & $\begin{array}{c}.064 \\
{[-.174, .286]}\end{array}$ & $\begin{array}{c}-.035 \\
{[-.271, .164]}\end{array}$ & $\begin{array}{c}.099 * * \\
{[.036, .183]} \\
\end{array}$ \\
\hline
\end{tabular}

Note. Study $1 N=499$. Study $2 N=298.95 \%$ confidence intervals are bias-corrected and based on 5,000 bootstrap samples.

Standardized estimates are reported. $\mathrm{HP}=$ harmonious passion. $\mathrm{OP}=$ obsessive passion. $\mathrm{SAV}=$ savoring. $\mathrm{EXH}=$

emotional/physical exhaustion. $\mathrm{RA}=$ reduced accomplishment. DEVAL $=$ sport devaluation. $* p \leq .05 . * * p \leq .01$. 


\section{Figure 1}

Standardized relationships between passion types, savoring, and burnout dimensions in Studies 1 and 2

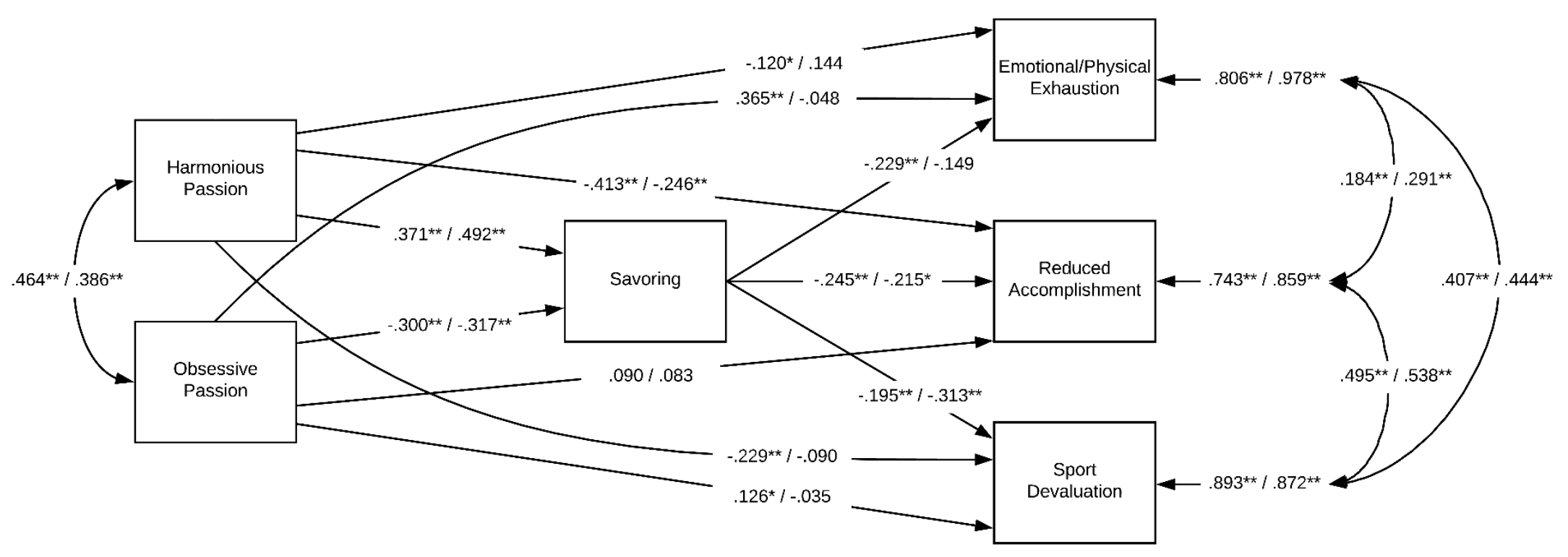

Note. Results for Study 1 (cross-sectional, $N=499$ ) are displayed before the slash, and results from Study 2 (prospective, $N=298$ ) are displayed after the slash. Residual variances of savoring (Study $1=.876$, Study $2=.778$ ) are not displayed for clarity.

$* p \leq .05 * * p \leq .01$ 